ISSN = 1980-993X - doi:10.4136/1980-993X
www.agro.unitau.br/ambi-agua
E-mail: ambi-agua@agro.unitau.br
Tel.: (12) 3625-4116

\title{
Caracterização temporal do arsênio nos cursos d'água da bacia hidrográfica do Rio das Velhas, MG, Brasil, ao longo de uma década (1998 - 2007)
}

(doi:10.4136/ambi-agua.102)

\author{
Cristiano Christofaro" ${ }^{1}$ Mônica Maria Diniz Leão ${ }^{2}$ \\ DESA - Departamento de Engenharia Sanitária e Ambiental - UFMG \\ E-mail: ${ }^{1}$ christofaro@gmail.com; ${ }^{2}$ monica@desa.ufmg.br
}

\section{RESUMO}

O arsênio é um metalóide com ampla distribuição na natureza, podendo ser encontrado nos ambientes naturais em formas de elevada toxicidade. Monitoramentos realizados na Bacia do Rio das Velhas, MG, demonstram a ocorrência desse metal em todas as estações de amostragem distribuídas ao longo de seu curso d'água principal e afluentes. Assim, o presente estudo objetiva avaliar as tendências temporais da concentração de arsênio nos cursos d'água da bacia do Rio das Velhas, considerando os dados das vinte e nove estações de monitoramento obtidos de 1998 a 2007. As análises incluíram a verificação da sazonalidade, autocorrelação e testes de tendência temporal não-paramétricos de Mann-Kendall e MannKendall Sazonal. Oito estações de amostragem apresentaram sazonalidade, com as maiores concentrações verificadas no período chuvoso. A autocorrelação foi praticamente inexistente, o que pode estar associado à baixa frequência amostral verificada no programa de monitoramento (três a seis meses). Apenas sete estações apresentaram tendência negativa significativa, indicando uma redução na concentração de arsênio ao longo do período estudado. Os resultados demonstraram que os estudos de tendência temporal apresentam grande relevância para a gestão da poluição dos recursos hídricos a partir de dados de monitoramento, fornecendo subsídios para medidas preventivas e corretivas diferenciadas entre as estações de amostragem e períodos do ano, podendo ainda ser utilizado na avaliação da efetividade dessas medidas.

Palavras-chave: Monitoramento; Qualidade da Água; Poluição Hídrica.

\section{Temporal characterization of Arsenic in das Velhas River hydrographic basin waters, MG, Brazil for one decade (1998 - 2007)}

\begin{abstract}
Arsenic, a metalloid with wide distribution in nature, can be found in natural environments in the forms of high toxicity. Monitoring conducted in the Basin of the das Velhas River, MG, demonstrates the occurrence of this metal in all sampling stations distributed over the water course and main tributaries. Thus, this study aims to evaluate the time trends of concentration of arsenic in water courses of the basin of das Velhas River, considering the data of twenty-nine monitoring stations from 1998 to 2007. The tests included the verification of seasonality, autocorrelation and temporal trend with the non-parametric tests of Mann-Kendall and Mann-Kendall seasonal. Eight sampling stations showed seasonality, with higher concentrations observed in rainy season. The autocorrelation was virtually nonexistent, which may be associated with low sample found in a monitoring program (three to six months). Only seven monitoring stations showed significant negative
\end{abstract}


CHRISTOFARO, C.; LEÃO, M. M. D. Caracterização temporal do arsênio nos cursos d'água da bacia hidrográfica do Rio das Velhas, MG, Brasil, ao longo de uma década (1998 - 2007). Ambi-Agua, Taubaté, v. 4 , n. 3, p. 54-66, 2009. (doi:10.4136/ambi-agua.102)

trend, indicating a reduction in the concentration of arsenic over the period studied. The results showed that the time trend studies have great relevance for the management of pollution of water resources from tracking data, providing subsidies for preventive and corrective measures differentiated between the stations and sampling periods of the year and also be used in evaluation of the effectiveness of these measures.

Keywords: Monitoring; Water Quality; Water Pollution.

\section{INTRODUÇÃO}

Estudos e monitoramentos da qualidade da água de longo prazo consistem em abordagens eficientes para um melhor conhecimento da hidrogeoquímica e poluição de cursos d'água. No entanto, esses estudos geram uma grande quantidade de dados distribuídos ao longo do tempo, cujas análises devem se valer de técnicas específicas de análise (Helsel e Hirsch, 2002; Shumway e Stoffer, 2006). A identificação da tendência temporal de um determinado conjunto de dados ambientais é importante tanto para a comunidade científica quanto para os órgãos de controle ambiental, uma vez que essa informação pode embasar atuações preventivas e corretivas. Dada sua importância para a gestão da qualidade dos recursos hídricos, estudos de tendências temporais vêm sendo executados em diferentes regiões do mundo (Antonopoulos et al., 2001; Richards e Baker, 2002; Meybeck, 2002; Simeonov et al., 2003; Dawe, 2006; Kannel et al., 2007; Groppo et al. 2008; Chang, 2008).

A bacia do Rio das Velhas, localizada na região central do Estado de Minas Gerais, compreende uma área de $29.173 \mathrm{Km}^{2}$, onde estão localizados 51 municípios que abrigam uma população de aproximadamente 4,8 milhões de habitantes. Nos últimos anos, os cursos de água dessa bacia vêm sendo monitorados no âmbito do Projeto "Águas de Minas". Com uma rede atual de 29 estações de amostragem, esse monitoramento indica a presença de poluentes relacionados tanto a fontes pontuais de poluição, representadas pelos esgotos sanitários, atividades de mineração e efluentes industriais, quanto a fontes difusas, representadas pela drenagem pluvial da área urbana e rural e por rejeitos de mineração (IGAM, 2008).

Dentre os diversos poluentes detectados na bacia do Rio das Velhas, destaca-se a ocorrência do arsênio em concentrações acima dos padrões ambientais - Resolução CONAMA 357/2005 (Brasil, 2005). Esse metalóide pode ser encontrado em variadas formas inorgânicas e orgânicas. Apresenta ampla distribuição na natureza, podendo estar associado a metais como cobre, níquel e ferro, ou ainda se apresentar na forma de sulfeto ou óxido de arsênico (WHO, 1981). A toxicidade do arsênio depende do estado químico verificado na sua exposição aos receptores. Enquanto o arsênio metálico e o sulfeto de arsênio são praticamente inertes, compostos metilados, resultantes de atividades biológicas, apresentam elevada toxicidade. Além da conhecida toxicidade, o arsênio é ainda considerado um elemento cancerígeno (Newman e Unger, 2002).

O presente estudo objetiva apresentar uma caracterização temporal do arsênio nos cursos d'água da bacia do Rio das Velhas, a partir dos dados obtidos em uma década de monitoramento (1998 a 2007), em vinte e nove estações . Especificamente será verificada a ocorrência de sazonalidade, autocorrelação e tendências temporais no período analisado.

\section{MATERIAL E MÉTODOS}

\section{1. Área de Estudo}

A bacia do Rio das Velhas está localizada na região central do Estado de Minas Gerais, entre as latitudes $17^{\circ} 15^{\prime} \mathrm{S}$ e $20^{\circ} 25^{\prime} \mathrm{S}$ e longitudes $43^{\circ} 25^{\prime} \mathrm{W}$ e $44^{\circ} 50^{\prime} \mathrm{W}$ (Figura 1 ). Apresenta uma forma alongada na direção norte-sul e corresponde à Unidade de Planejamento e Gestão de Recursos Hídricos SF5 (São Francisco 5). O Rio das Velhas tem sua nascente 
CHRISTOFARO, C.; LEÃO, M. M. D. Caracterização temporal do arsênio nos cursos d'água da bacia hidrográfica do Rio das Velhas, MG, Brasil, ao longo de uma década (1998 - 2007). Ambi-Agua, Taubaté, v. 4 , n. 3, p. 54-66, 2009. (doi:10.4136/ambi-agua.102)

principal na cachoeira das Andorinhas, município de Ouro Preto, numa altitude de aproximadamente $1.500 \mathrm{~m}$. Toda a bacia compreende uma área de drenagem oficial de 29.173 $\mathrm{Km}^{2}$, onde estão localizados 51 municípios que abrigam uma população de aproximadamente 4,8 milhões de habitantes (destes, aproximadamente $89 \%$ residem em distritos e municípios integralmente inseridos na bacia). O Rio das Velhas encontra-se com o rio São Francisco em Barra do Guaicuí, Distrito de Várzea da Palma, numa altitude de 478 m (IGAM, 2008).

Para fins de gerenciamento ambiental, a bacia do Rio das Velhas pode ser dividida em trechos alto, médio e baixo. O alto Rio das Velhas corresponde a cerca de 9,8\% da área de drenagem da bacia, compreendendo o Quadrilátero Ferrífero, amplamente explorado por atividades minerárias. Esse trecho é delimitado, ao sul, pelo município de Ouro Preto e, ao norte, pelos municípios de Belo Horizonte, Contagem e Sabará. Apresenta o maior contingente populacional da bacia (cerca de $70 \%$ da população), com uma expressiva atividade econômica, concentrada na Região Metropolitana de Belo Horizonte, onde estão presentes os maiores focos de poluição hídrica da bacia. Os trechos médio e baixo Rio das Velhas correspondem, respectivamente, a $45 \%$ e $45,2 \%$ da área de drenagem da bacia, apresentando características diferenciadas, incluindo uma menor concentração populacional ( $25 \%$ da população da bacia no trecho médio e $5 \%$ no trecho baixo), com o predomínio das atividades agrícolas e pecuárias. O médio Rio das Velhas inicia-se após a foz do ribeirão da Mata, seguindo até a foz do rio Paraúna. O baixo Rio das Velhas inicia-se após a confluência com o rio Paraúna e vai até sua foz, no Rio São Francisco (Camargos, 2004).

$\mathrm{Na}$ bacia do Rio das Velhas os tipos climáticos diferenciam-se ao longo de seus trechos. Em geral, a bacia do Rio das Velhas apresenta uma queda das precipitações médias no caminhamento sul para norte, os máximos das precipitações são observados nas nascentes localizadas na serra de Ouro Preto, onde a ocorrência de fenômenos orográficos mantém a média anual em torno de $2.000 \mathrm{~mm}$. As médias anuais de temperatura na bacia variam entre $18^{\circ} \mathrm{C}$, na região das cabeceiras, até $23^{\circ} \mathrm{C}$ no extremo norte, junto à foz no rio São Francisco. Em relação ao comportamento sazonal das precipitações na bacia, distinguem-se 3 meses secos: junho, julho e agosto. A exceção é verificada no alto Rio das Velhas, que passa por períodos secos maiores, que variam de 4 a 5 meses (maio a setembro) (Camargos, 2004).

Desde 1997, a bacia hidrográfica do Rio das Velhas vem sendo monitorada no âmbito do programa “Águas de Minas” (IGAM, 2008). Nesse programa, 29 (vinte e nove) estações de amostragem são utilizadas para o monitoramento do arsênio na bacia do Rio das Velhas (Figura 1), com frequência de amostragem trimestral ou semestral. Para a análise de tendência foram utilizados os dados do arsênio coletados de 1998 a 2007 nas 29 estações de amostragem localizadas ao longo do Rio das Velhas e afluentes.

\subsection{Análises}

Uma série temporal pode ser definida como um conjunto de informações arranjadas em ordem cronológica (Hipel e McLeod, 1994). Assim, pode-se concluir que a ordem de ocorrência das observações é crucial para a análise de séries temporais. Baseadas nessa premissa, diversas técnicas e métodos de análise de séries temporais foram desenvolvidas e aplicadas (Hipel e McLeod, 1994; Helsel e Hitch, 2002; Berthouex e Brown, 2002). No presente estudo, a análise das séries temporais valeu-se dos seguintes passos: caracterização dos dados por período do ano, teste de Kruskall-Wallis para verificar diferenças significativas entre as estações do ano, verificação da autocorrelação da série temporal e testes de tendências temporais. 
CHRISTOFARO, C.; LEÃO, M. M. D. Caracterização temporal do arsênio nos cursos d'água da bacia hidrográfica do Rio das Velhas, MG, Brasil, ao longo de uma década (1998 - 2007). Ambi-Agua, Taubaté, v. 4, n. 3, p. 54-66, 2009. (doi:10.4136/ambi-agua.102)

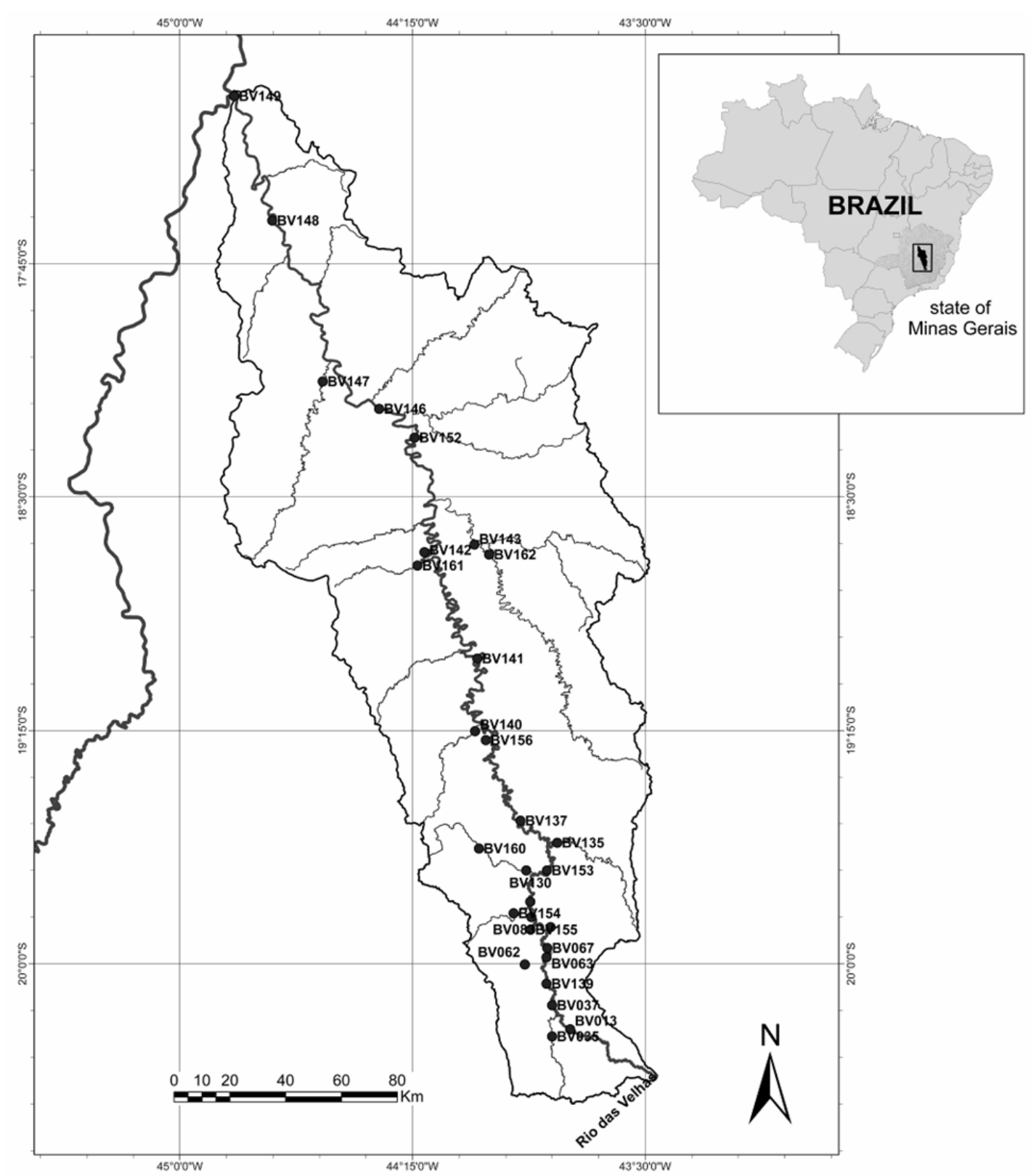

Figura 1. Localização em Minas Gerais e disposição das estações de amostragem do arsênio na bacia hidrográfica do Rio das Velhas, MG, no âmbito do programa "Água de Minas". Elaborado a partir dos dados disponíveis em IGAM (2008).

Após a caracterização geral dos dados em boxplots, considerando o curso d'água principal e os afluentes monitorados, os dados foram plotados por trimestre ou semestre, de acordo com a frequência de coleta adotada na respectiva estação de amostragem. Assim, para fins das análises subsequentes, cada semestre ou trimestre de coleta passou a ser considerado uma estação do ano. De acordo com Helsel e Hirsch (2002), a utilização de boxplots consiste no método gráfico mais adequado para representação da sazonalidade, principalmente nos casos em que se verifica um padrão único de tendência em todas as estações do ano.

A seguir, o teste de Kruskall-Wallis (KW) foi utilizado para a verificação de diferenças significativas entre os trimestres, ou semestres, em que foram realizadas as coletas. Uma vez verificada diferença significativa entre os períodos do ano, considerou-se que a série de dados apresenta sazonalidade. A sazonalidade consiste em uma fonte potencialmente elevada de variação nas séries de dados de qualidade da água. Assim, seus efeitos devem ser compensados ou "removidos" de forma a permitir uma melhor caracterização das tendências 
CHRISTOFARO, C.; LEÃO, M. M. D. Caracterização temporal do arsênio nos cursos d'água da bacia hidrográfica do Rio das Velhas, MG, Brasil, ao longo de uma década (1998 - 2007). Ambi-Agua, Taubaté, v. 4 , n. 3, p. 54-66, 2009. (doi:10.4136/ambi-agua.102)

temporais. Caso contrário, os testes estatísticos subsequentes podem apresentar pouco poder de detecção das tendências eventualmente existentes na série analisada (Helsel e Hirsch, 2002).

A ocorrência de autocorrelação foi verificada pela aplicação da Função de Autocorrelação (FAC) (Hipel e McLeod, 1994; Berthouex e Brown, 2002). A função de autocorrelação mede o grau de correlação de uma variável, em um dado instante, consigo mesma em um instante de tempo posterior. A verificação da autocorrelação é um pré-requisito de muitos testes de tendência a fim de se evitar a falsa detecção de tendências (Hipel e McLeod, 1994).

A verificação das tendências temporais foi feita a partir do teste de tendências de MannKendall (MK) ou teste sazonal de tendências de Mann-Kendall (SMK), de acordo com a ocorrência de sazonalidade. Tais testes, não-paramétricos, são adequados para utilização nos casos em que são verificadas tendências monotônicas e também naqueles em que não são feitas correções de variáveis exógenas, como a vazão, que influenciam na variação da série temporal. Por apresentarem robustez, lidarem bem com falhas nas séries de dados e com dados abaixo do limite de detecção, o MK e o SMK são frequentemente utilizados em estudos ambientais para verificação de tendências monotônicas (Helsel e Hitch, 2002).

Nos casos em que em que o valor de ' $\mathrm{p}$ ' do teste $\mathrm{KW}$ para sazonalidade não foi considerado significativo ( $\mathrm{p}>0,05)$, verificou-se a ocorrência de tendência temporal por meio do teste Mann-Kendall (MK). Esse teste não-paramétrico, criado na década de 1945, tem como idéia principal a determinação do sinal das diferenças pareadas entre as amostragens consecutivas de uma série temporal, sendo esse sinal correspondente à tendência (negativa ou positiva) da série de dados (Hess et al. 2001).

Nos casos em que foram verificados valores significativos de $p$ no teste $K W(p \leq 0,05)$, utilizou-se o teste Sazonal de Mann-Kendall (SMK) para verificar a existência de tendência nas séries temporais em cada estação de amostragem, no período analisado. O SMK consiste em uma variação do teste MK no qual a estatística $\tau$ de Kendall é calculada considerando-se a existência de sazonalidade na série de dados. Todos os testes relativos à análise de tendências temporais foram executados no programa R (v. 2.8.1) (R Development Core Team, 2008), juntamente com o pacote "Kendall" (McLeod, 2005).

\section{RESULTADOS E DISCUSSÃO}

\subsection{Caracterização do arsênio nos cursos d'água}

As concentrações medianas, o primeiro e o terceiro percentil e os outliers mensurados em cada estação de amostragem de arsênio podem ser visualizados na Figura 2. O teste Kruskall-Wallis demonstrou que as concentrações de arsênio obtidas nas diferentes estações de amostragem apresentam diferença significativa entre si. Todas as estações apresentaram outliers, com maior frequência nas estações BV035 e BV037, ambas sob influência do rio Itabirito. A maior ocorrência de outliers nesses pontos pode indicar ocorrência de atividades com duração limitada e frequência irregular, e que sua influência estaria restrita à área de influência do rio Itabirito. 
CHRISTOFARO, C.; LEÃO, M. M. D. Caracterização temporal do arsênio nos cursos d'água da bacia hidrográfica do Rio das Velhas, MG, Brasil, ao longo de uma década (1998 - 2007). Ambi-Agua, Taubaté, v. 4, n. 3, p. 54-66, 2009. (doi:10.4136/ambi-agua.102)
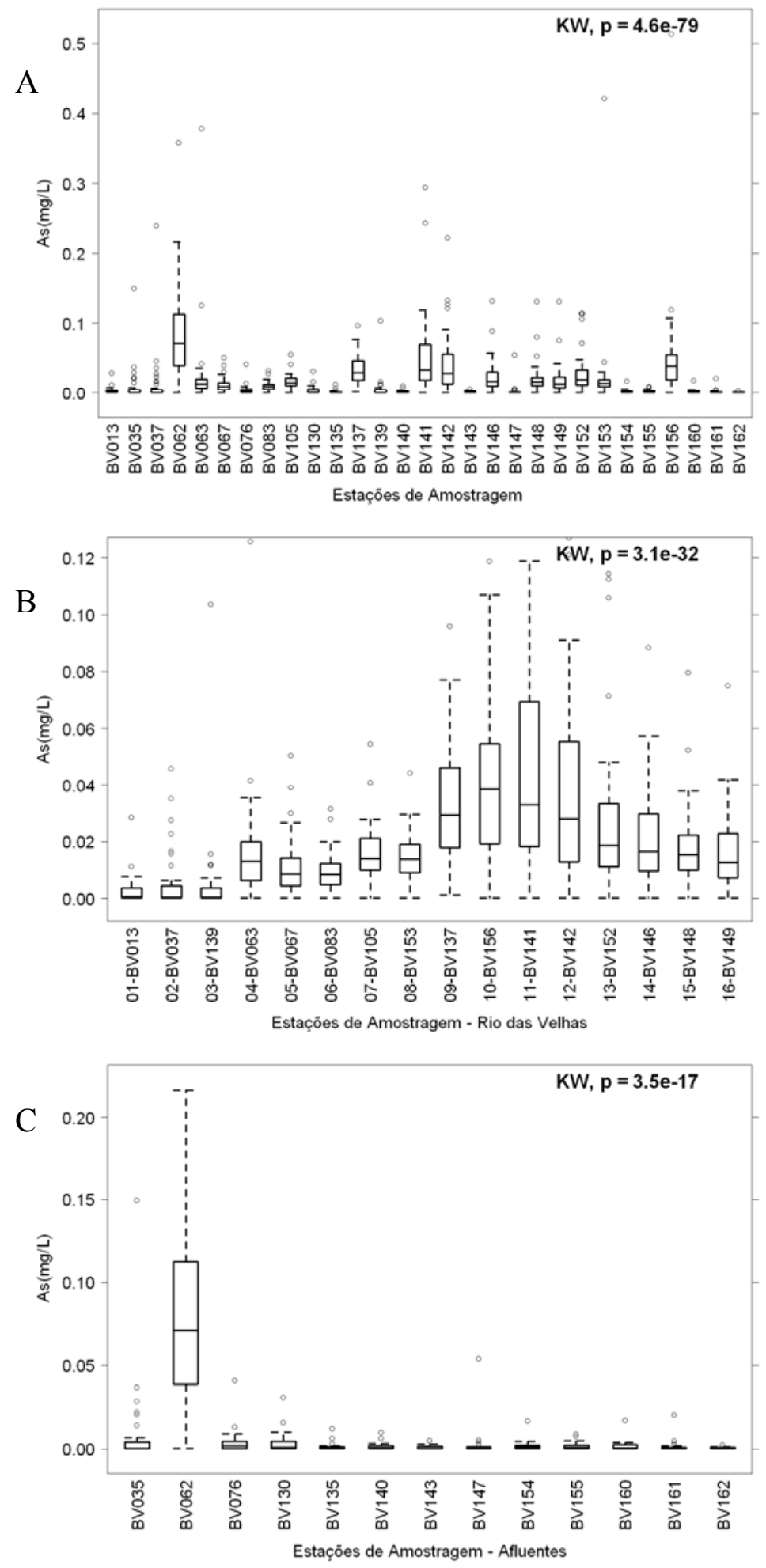

Figura 2. Boxplots com as concentrações de arsênio verificadas nas estações de amostragem da bacia hidrográfica do Rio das Velhas de 1998 a 2007. A - Todas as estações de amostragem. B - Curso d'água principal ordenado de montante para jusante, sem a influência dos outliers na escala. C - Afluentes, sem influência dos outliers na escala.

No curso d'água principal, verifica-se que as concentrações de arsênio apresentam um aumento praticamente constante da estação localizada mais à montante (BV013) até o trecho 
situado entre as estações BV137 e BV142, onde foram verificadas as maiores concentrações desse metal. A partir desse ponto, verifica-se uma redução na concentração de arsênio, porém insuficiente para igualar-se às condições verificadas no trecho inicial do rio (Figura 2B). $\mathrm{O}$ teste de Kruskall-Wallis indicou diferença significativa entre as medianas das concentrações verificadas nas estações de amostragem situadas ao longo do curso d'água principal.

Nos afluentes, as maiores concentrações medianas e máximas de arsênio são verificadas na estação BV062, correspondente ao afluente denominado Ribeirão Água Suja. Esse ponto também apresentou as maiores concentrações medianas de toda a bacia. Nos demais afluentes, as concentrações foram relativamente menores do que aquelas verificadas no curso d'água principal (Figura 2C). As medianas das concentrações dos afluentes apresentaram diferença significativa entre si, de acordo com a comparação realizada pelo teste de Kruskall-Wallis. A análise visual indica que a diferença detectada deve-se às medianas obtidas para a estação BV062.

\subsection{Sazonalidade}

A Figura 3 apresenta boxplots das concentrações de arsênio em cada um dos trimestres/semestres em que as coletas foram executadas, bem como os resultados do teste Kruskall-Wallis para verificação da sazonalidade. Os gráficos que apresentam dois trimestres indicam coleta semestral. A ocorrência de três trimestres em três estações de amostragem deve-se ao aumento da frequência de coleta para essas estações específicas iniciado no último trimestre de 2007.
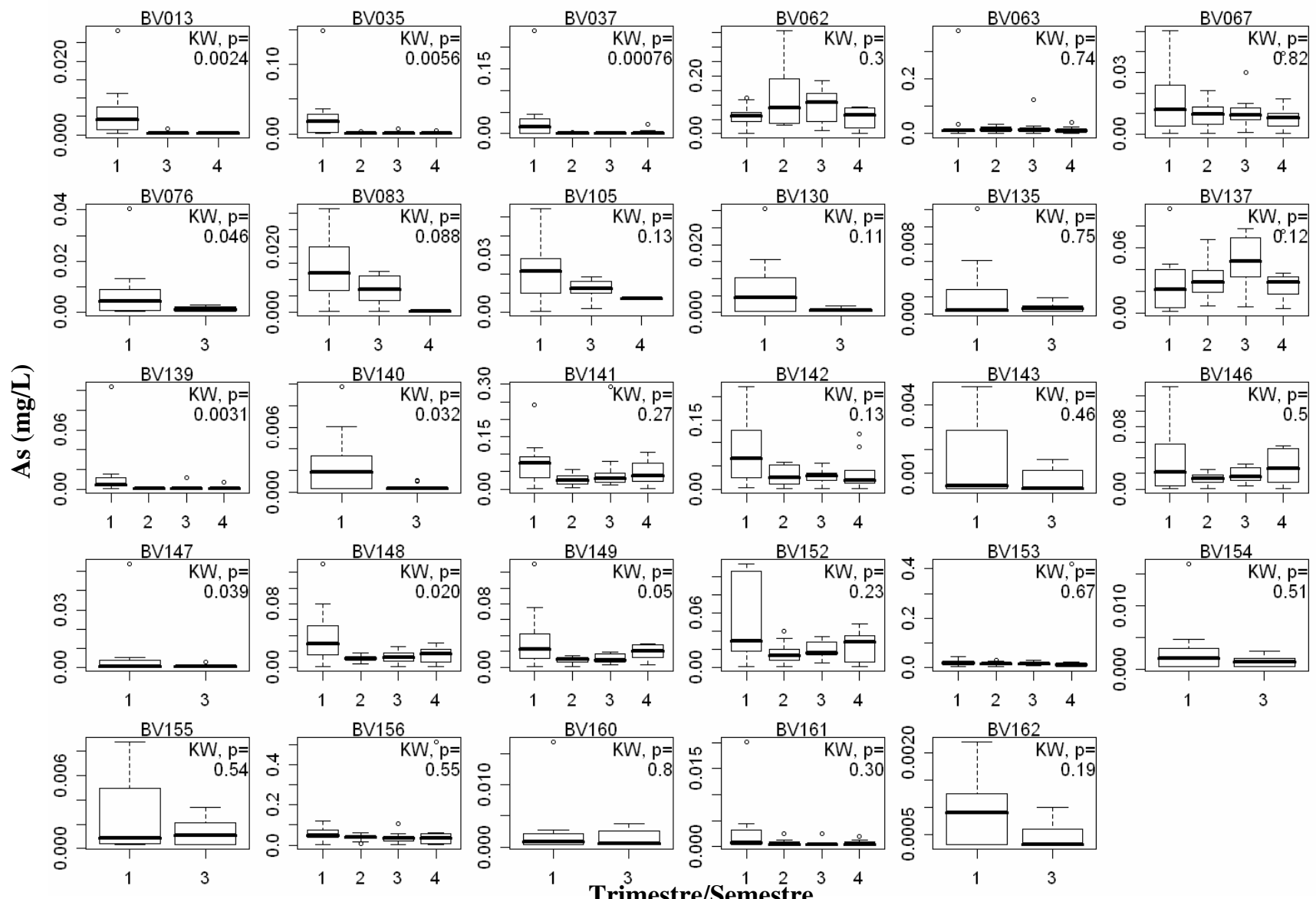

Figura 3. Boxplots e teste Kruskall-Wallis das concentrações de Arsênio por trimestre/semestre nas estações de amostragem da bacia hidrográfica do Rio das Velhas. Valores de $p$ abaixo de 0,05 indicam diferença significativa entre as concentrações verificadas por período considerado. 
Os resultados do teste de Kruskall-Wallis indicaram a ocorrência de sazonalidade em sete estações de amostragem: BV013, BV035, BV037, BV139, BV147, BV148, BV149. Com exceção das estações BV035 e BV147, todas se encontram no curso d'água principal. Percebe-se ainda que as quatro primeiras estações de amostragem citadas correspondem exatamente às quatro estação mais a montante da bacia, enquanto que as demais correspondem às três estações mais a jusante. Assim, a sazonalidade para o arsênio foi verificada apenas nas estações de amostragem mais próximas à nascente e à foz do Rio das Velhas.

Em todos os casos que foi verificada sazonalidade significativa, as maiores concentrações são verificadas no primeiro trimestre/semestre (Figura 3). Uma vez que nesse período verifica-se a maior abundância de chuva na bacia, o aumento na concentração pode estar relacionado à predominância da lixiviação do solo em relação à diluição causada pela chuva, ou seja, pode estar ligada à ocorrência de poluição difusa.

\subsection{Tendências temporais}

De uma maneira geral, o coeficiente de autocorrelação não alcançou valores significativos para o arsênio (Figura 4).
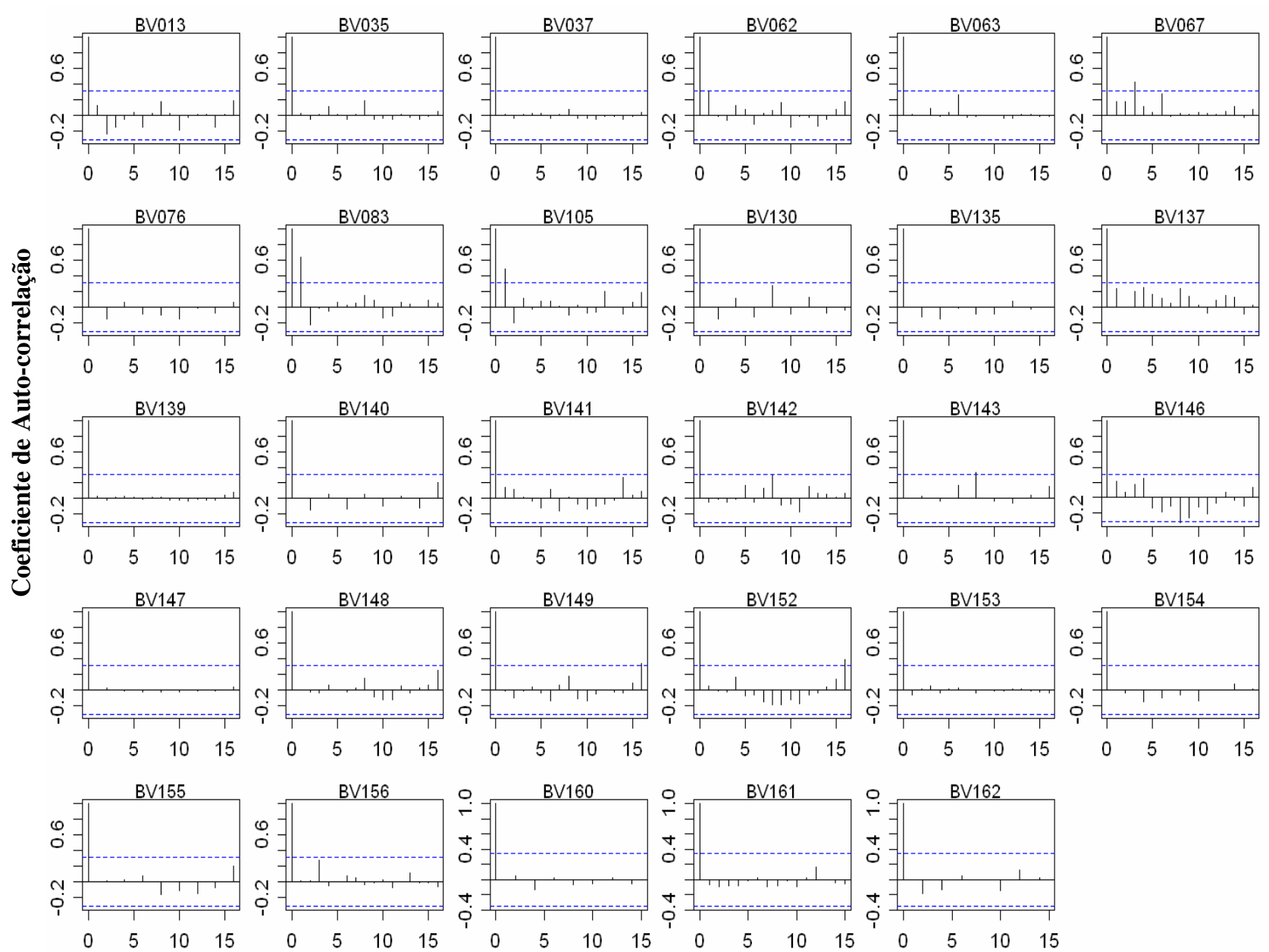

Atraso (lag)

Figura 4. Coeficientes da Função de Autocorrelação (FAC) do arsênio, considerando coletas trimestrais ou semestrais, nas estações de amostragem da bacia hidrográfica do Rio das Velhas. As linhas tracejadas indicam valores estatisticamente significativos.

O longo lapso temporal entre as amostragens, de trimestral a semestral, pode explicar a ausência de autocorrelação verificada em todas as amostras (Berthouex e Brown, 2002). 
Nesse contexto, a ausência de autocorrelação indica que os dados podem ainda comportar um aumento na frequência de coleta sem resultar em dados correlacionados entre si, o que poderia agregar novas informações aos resultados.

A Figura 5 apresenta as tendências temporais do arsênio nas séries de dados, bem como os resultados dos testes MK ou SMK, realizados em cada um dos 29 pontos de amostragem.
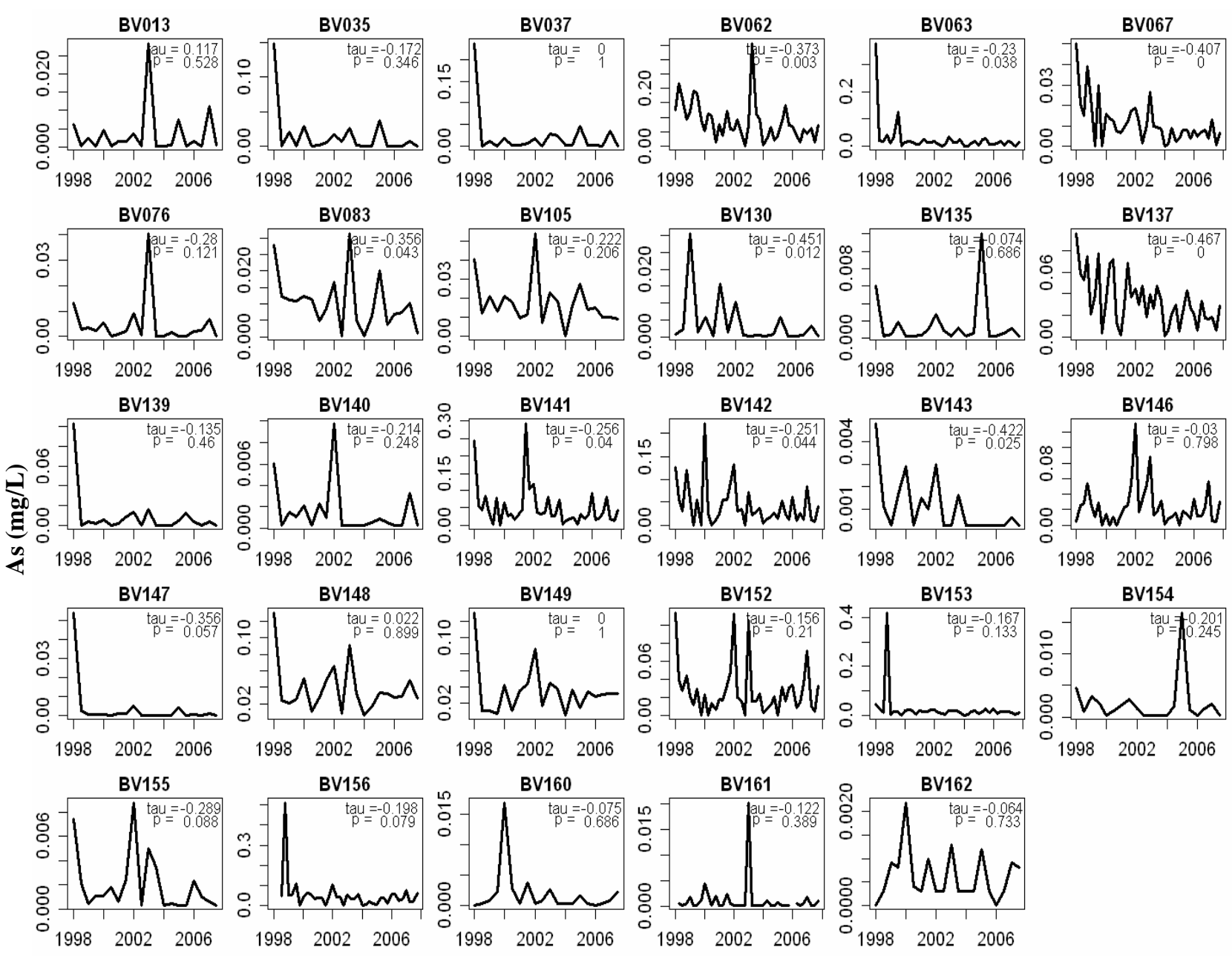

\section{Ano}

Figura 5. Tendências temporais do arsênio de 1998 a 2007 e resultado do teste de Mann-Kendall e Sazonal de Mann-Kendall nas estações de amostragem das águas superficiais da bacia hidrográfica do Rio das Velhas.

Os resultados indicam que nove estações de amostragem apresentaram tendência negativa $(p \leq 0,05)$ no período analisado (Figura 5). Três dessas estações estão localizadas em afluentes: BV062 (Ribeirão Água Suja), BV130 (Ribeirão da Mata) e BV143 (Rio Paraúna). As outras seis estações de amostragem estão distribuídas no trecho alto e médio do curso d'água principal: BV063, BV067, BV083, BV137, BV141 e BV142. As demais estações de amostragem não apresentaram tendências temporais para o arsênio de acordo com os critérios utilizados. Os resultados da sazonalidade e da tendência temporal, nas vinte e nove estações de amostragem distribuídas ao longo da bacia do Rio das Velhas, são resumidos na Tabela 1. 
CHRISTOFARO, C.; LEÃO, M. M. D. Caracterização temporal do arsênio nos cursos d'água da bacia hidrográfica do Rio das Velhas, MG, Brasil, ao longo de uma década (1998 - 2007). Ambi-Agua, Taubaté, v. 4 , n. 3, p. 54-66, 2009. (doi:10.4136/ambi-agua.102)

Tabela 1. Resumo da sazonalidade e das tendências temporais do arsênio nas estações de monitoramento da bacia do Rio das Velhas/MG. $\mathrm{S}=$ Sazonalidade significativa. $\downarrow=$ Tendência negativa significativa.

\begin{tabular}{cccc}
\hline Estação & Descrição & $\begin{array}{c}\text { Trecho } \\
\text { da Bacia }\end{array}$ & $\begin{array}{c}\text { Sazonalidade/ } \\
\text { Tendência }\end{array}$ \\
\hline BV013 & Rio das Velhas & & $\mathrm{S}$ \\
BV035 & Rio Itabirito & & $\mathrm{S}$ \\
BV037 & Rio das Velhas & & $\mathrm{S}$ \\
BV062 & Ribeirão Água Suja & & $\downarrow$ \\
BV063 & Rio das Velhas & & $\downarrow$ \\
BV067 & Rio das Velhas & Alto & \\
BV076 & Ribeirão Sabará & & $\downarrow$ \\
BV083 & Rio das Velhas & & \\
BV105 & Rio das Velhas & & \\
BV139 & Rio das Velhas & & \\
BV154 & Ribeirão do Onça & & $\downarrow$ \\
BV155 & Ribeirão Arrudas & \\
\hline BV130 & Ribeirão da Mata & & $\downarrow$ \\
BV135 & Rio Taquaraçu & & $\downarrow$ \\
BV137 & Rio das Velhas & & $\downarrow$ \\
BV140 & Ribeirão Jequitibá & & \\
BV141 & Rio das Velhas & & \\
BV142 & Rio das Velhas & Médio & \\
BV143 & Rio Paraúna & & \\
BV153 & Rio das Velhas & & \\
BV156 & Rio das Velhas & & \\
BV160 & Ribeirão das Neves & & \\
BV161 & Ribeirão Santo Antônio & & \\
BV162 & Rio Cipó & & \\
\hline BV146 & Rio das Velhas & & \\
BV147 & Rio Bicudo & & \\
BV148 & Rio das Velhas & Baixo & \\
BV149 & Rio das Velhas & & \\
BV152 & Rio das Velhas & & \\
\hline
\end{tabular}

Deve-se destacar que quatro das cinco maiores concentrações mensuradas na bacia (BV062, BV137, BV141 e BV142) (Figura 2) estão entre aquelas que apresentaram tendência negativa, ou seja, apresentaram redução nas concentrações de arsênio no período analisado. As estações de amostragem BV141 e BV142 são contíguas, indicando uma melhoria em parte do trecho médio do Rio das Velhas. Essa melhoria pode estar associada a um controle mais efetivo das atividades poluidoras na região, principalmente no que diz respeito à mineração (nas proximidades da estação de amostragem BV137) e atividades agrícolas (BV141 e BV142), com possível redução da carga poluidora difusa. A redução na concentração de arsênio na estação de amostragem BV062 (Ribeirão Água Suja) possivelmente está associada a um maior controle de fontes de efluentes sanitários, uma vez que esse curso d'água se encontra em uma área densamente povoada.

Deve-se destacar que nenhuma das estações de amostragem com tendência significativa apresentou sazonalidade (Figuras 3 e 5). Esse fato indica que a redução na concentração desse metal pode estar ocorrendo em todas as estações do ano. Em geral, os resultados indicam que, com exceção das nove estações de amostragem onde se detectou a ocorrência de tendência negativa, os cursos d'água da bacia do Rio das Velhas apresentaram concentrações estáveis de arsênio ao longo do período analisado. No entanto, de acordo com Helsel e Hirsch (2002) 
CHRISTOFARO, C.; LEÃO, M. M. D. Caracterização temporal do arsênio nos cursos d'água da bacia hidrográfica do Rio das Velhas, MG, Brasil, ao longo de uma década (1998 - 2007). Ambi-Agua, Taubaté, v. 4 , n. 3, p. 54-66, 2009. (doi:10.4136/ambi-agua.102)

resultados negativos para a rejeição da hipótese nula nesses testes não provam a ausência de tendência. Nesses casos, pode-se concluir que as evidências disponíveis não são suficientes para concluir que existe uma tendência.

Os testes MK e SMK apresentam como desvantagem o fato de serem aplicados apenas a dados univariados, não sendo aplicáveis à avaliação de múltiplas fontes simultâneas de variação. Nessa situação, recomenda-se a utilização de análises de regressão multivariadas. No caso específico do teste SMK, outra desvantagem inclui o fato de que o resultado final consiste em uma média dos valores verificados em cada estação do ano. Assim, fortes tendências contrárias nas diversas estações do ano podem se anular, gerando uma falsa ausência de tendência no resultado final do teste (Helsel e Hirsch, 2002).

As vantagens desse teste incluem todas aquelas associadas a testes não-paramétricos, tais como: imunidade a transformações nos dados, robustez, bom desempenho no caso de falhas nas séries de dados, outliers e nos casos de dados abaixo do limite de detecção (Helsel e Hirsch, 2002). Além disso, a flexibilidade de incorporar dados com diferentes distribuições de probabilidade faz com que os testes MK e SMK sejam vantajosos em relação a testes baseados em regressão linear, que exigem que os resíduos apresentem distribuição normal (Helsel e Frans, 2006).

\section{CONCLUSÃO}

Os testes Mann-Kendall e Mann-Kendall Sazonal, com 95\% de confiança, demonstram que, entre 1998 e 2007, as concentrações de arsênio apresentaram tendência de redução em nove estações de amostragem monitoradas.

Apenas sete estações de monitoramento apresentaram comportamento sazonal. Porém, nenhuma delas apresentou qualquer tipo de tendência ao longo do período analisado. Desse modo, eventuais medidas de controle da contaminação pelo arsênio não devem estar restritas a épocas específicas do ano.

A ausência de autocorrelação nas séries analisadas, apesar de ser uma condição desejável para as análises de tendências temporais, pode indicar que um aumento na frequência de amostragem pode vir a melhorar a caracterização do arsênio ao longo do tempo. Assim, esse aumento deve ser considerado nas amostragens futuras.

Além embasar medidas preventivas e/ou corretivas diferenciadas entre as estações de amostragem e períodos do ano, a caracterização temporal dos dados pode permitir a avaliação da eficiência de medidas de controle adotadas por meio da análise de tendência.

Por fim, as limitações associadas aos testes utilizados devem ser levadas em consideração na interpretação dos dados, incluindo sua restrição à caracterização de tendências monotônicas e, no caso do teste sazonal de tendências, a possibilidade de interferência dos resultados obtidos em cada estação do ano no valor final do teste (Helsel e Hirsch, 2002).

Os resultados do estudo demonstram o potencial de utilização da caracterização temporal dos dados de monitoramento como ferramenta de auxílio à gestão da qualidade das águas em bacias hidrográficas.

\section{REFERÊNCIAS}

ANTONOPOULOS, V. Z.; PAPAMICHAIL, D. M.; MITSIOU, K. A. Statistical and trend analysis of water quality and quantity data for the strymon river in greece. Hydrol. Earth Syst. Sci., v. 5, n. 4, p.679-692, 2001. 
CHRISTOFARO, C.; LEÃO, M. M. D. Caracterização temporal do arsênio nos cursos d'água da bacia hidrográfica do Rio das Velhas, MG, Brasil, ao longo de uma década (1998 - 2007). Ambi-Agua, Taubaté, v. 4 , n. 3, p. 54-66, 2009. (doi:10.4136/ambi-agua.102)

BERTHOUEX, P. M.; BROWN, L. C. Statistics for environmental engineers. 2. ed. Boca Raton: CRC, 2002.

BRASIL. Ministério do Meio Ambiente. Resolução CONAMA nº 357, de 17 de março de 2005. Dispõe sobre a classificação dos corpos de água e diretrizes ambientais para seu enquadramento, bem como estabelece as condições e padrões de lançamento de efluentes, e dá outras providências. Disponível em: <http://www.mma.gov.br>. Acesso: 09 julho 2009.

CAMARGOS, L. M. M. Plano diretor de recursos hídricos da bacia hidrográfica do Rio das Velhas: resumo executivo. Belo Horizonte: Instituto Mineiro de Gestão das Águas, Comitê da Bacia Hidrográfica do Rio das Velhas, 2004.

CHANG, H. Spatial analysis of water quality trends in the han river basin, south korea. Water Research, v. 42, n. 13, p. 3285-3304, 2008.

DAWE, P. A statistical evaluation of water quality trends in selected water bodies of newfoundland and labrador. Journal of Environmental Engineering and Science, v. 5, p. 59-73, 2006.

GROPPO, J. D.; MORAES, J. M. D.; BEDUSCHI, C. E.; GENOVEZ, A. M.; MARTINELLI, L. A. Trend analysis of water quality in some rivers with different degrees of development within the são paulo state, brazil. River Research and Applications, v. 24, n. 8, p. 1056-1067, 2008.

HESS, A.; IYER, H.; MALMB, W. Linear trend analysis: a comparison of methods. Atmospheric Environment, v. 35, p. 5211-5222, 2001.

HELSEL, D. R.; FRANS, L. M. Regional Kendall test for trend. 2006. Disponível em: $<$ http://pubs.acs.org/doi/abs/10.1021/es051650b?prevSearch=helsel\&searchHistoryKey $=>$. Acesso: 09 junho 2009 .

HELSEL, D. R.; HIRSCH, R. M. Statistical methods in water resources. Amsterdam: Elsevier Science, 2002.

HIPEL, K. W.; MCLEOD, A. I. Time series modelling of water resources and environmental systems. Amsterdam: Elsevier Science, 1994.

INSTITUTO MINEIRO DE GESTÃO DAS ÁGUAS - IGAM. Monitoramento das águas Superficiais na Bacia do Rio das Velhas 1998-2007. Belo Horizonte: IGAM, 2008. $161 \mathrm{p}$.

KANNEL, P.; LEE, S.; KANEL, S.; KHAN, S.; LEE, Y. Spatial-temporal variation and comparative assessment of water qualities of urban river system: a case study of the river Bagmati (Nepal). Environmental Monitoring and Assessment, v. 129, n. 1, p. 433-459, 2007.

MCLEOD, A. Kendall: Kendall rank correlation and Mann-Kendall trend test. 2005. Disponível em: <http://www.stats.uwo.ca/faculty/aim>. Acesso: 09 julho 2009.

MEYBECK, M. Riverine quality at the anthropocene: propositions for global space and time analysis, illustrated by the seine river. Aquatic Sciences - Research Across Boundaries, v. 64, n. 4, p. 376-393, 2002.

NEWMAN, M. C.; UNGER, M. A. Fundamentals of ecotoxicology. 2. ed. Boca Raton: CRC, 2002. 
CHRISTOFARO, C.; LEÃO, M. M. D. Caracterização temporal do arsênio nos cursos d'água da bacia hidrográfica do Rio das Velhas, MG, Brasil, ao longo de uma década (1998 - 2007). Ambi-Agua, Taubaté, v. 4 , n. 3, p. 54-66, 2009. (doi:10.4136/ambi-agua.102)

R DEVELOPMENT CORE TEAM. R: a language and environment for statistical computing. Vienna, 2008. Disponível em: <http://www.R-project.org>. Acesso: 08 dez 2008.

RICHARDS, R. P.; BAKER, D. B. Trends in water quality in leaseq rivers and streams (northwestern ohio), 1975-1995. J Environ Qual, v. 31, n. 1, p. 90-96, 2002.

SHUMWAY, R. H.; STOFFER, D. S. Time series analysis and its applications: with R examples. 2. ed. New York: Springer, 2006.

SIMEONOV, V.; STRATIS, J. A.; SAMARA, C.; ZACHARIADIS, G.; VOUTSA, D.; ANTHEMIDIS, A.; SOFONIOU, M.; KOUIMTZIS, T. Assessment of the surface water quality in northern greece. Water Research, v. 37, n. 17, p. 4119-4124, 2003.

WORLD HEALTH ORGANIZATION - WHO. Arsenic. Environmental Health Criteria 18. International Programme on Chemical Safety - IPCS. Geneva: WHO, 1981. 